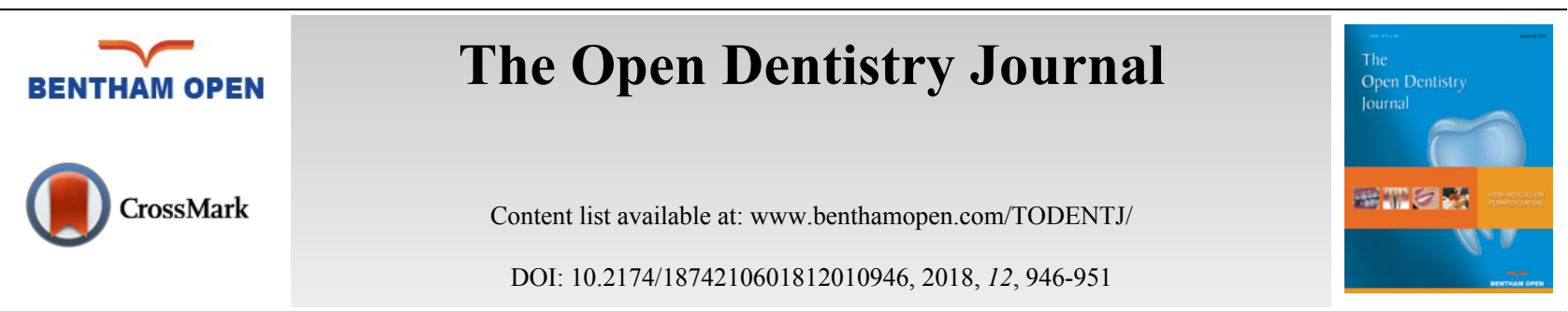

RESEARCH ARTICLE

\title{
Effect of Oil Paint Addition on Impact Strength of the Scleral Part of the Acrylic Ocular Prosthesis
}

\author{
Firas Abd Kati \\ Department of Optical techniques, College of Health \& Medical Technology, Middle Technical University, Baghdad, \\ Iraq
}

Received: August 7, 2018

Revised: October 8, 2018

Accepted: October 17, 2018

\section{Abstract: \\ Background:}

For many dental and facial restorations, acrylic resins are the materials of choice because of their appropriate physical and mechanical properties. When making the ocular prosthesis from such materials, it is essential to add the perfect shade in order to match the colour of normal eye. This, however, might have a significant effect on the mechanical properties of acrylic resins.

\section{Objective:}

The purpose of this study was to assess the effect of adding the white oil paint (titanium dioxide) to clear acrylic resins on their impact strength.

\section{Methods:}

20 samples were constructed from heat cured acrylic resins, and divided into two groups (control and experimental) and each group had 10 samples. The first group was made from clear acrylic resin without the addition of white oil paints, and the second group (experimental) comprised the addition of $1 \mathrm{ml}$ of the white oil paints to acrylic samples. Such samples were prepared with dimensions of $(80 \mathrm{~mm}$ X10 $\mathrm{mm} \mathrm{X4} \mathrm{mm)} \mathrm{length,} \mathrm{width,} \mathrm{and} \mathrm{thickness,} \mathrm{respectively.} \mathrm{All} \mathrm{the} \mathrm{samples} \mathrm{were} \mathrm{tested} \mathrm{by} \mathrm{the} \mathrm{Charpy's}$ impact strength test. They were exposed to the load till the fracture occurred. All the values were analyzed using SPSS version 20 , and the independent T-test was used for comparison between the 2 groups.

\section{Results:}

A statistically significant decrease $(P$-value $<0.001)$ was found in the impact strength of acrylic resins after the addition of titanium dioxide oil paints (experimental group: $5.97+1.11$, control group: $9.42+1.32 \mathrm{KJ} / \mathrm{M}^{2}$ ).

\section{Conclusion:}

This study concluded that the addition of titanium dioxide oil paint significantly reduces the impact of strength of the acrylic resin. It is suggested to use different stains which will have no negative effect on impact strength of the acrylic resin.

Keywords: Acrylic resin, Oil paints, Impact strength, Titanium dioxide, SPSS version 20, Dental and facial restorations.

\section{INTRODUCTION}

Tumour (i.e. squamous cell carcinoma), trauma (i.e. motor accidents) and congenital deformity (i.e. anophthalmia) are the main causes of eye defects, which have a negative impact on the emotional and social life of the patient [1,2]. The construction of artificial eyes can preserve the volume of the eye socket, make the patient confident in public and

* Address correspondence to this author at the Department of Optical techniques, College of Health \& Medical Technology, Middle Technical University, Baghdad, Iraq; Tel +077 18562575; E-mail: firas_abd26@yahoo.com 
restore the natural appearance for the patient [3, 4]. Basically, artificial eyes are either readymade or can be manufactured by the maxillofacial technician; and each kind has its benefits and drawbacks. For example, readymade prostheses have poor fit and are used temporarily in spite of restoring the normal appearance for the patients. The custom-made ocular prostheses are mainly constructed from polymethyl methacrylate and can fit the eye socket and reestablish aesthetics $[5,6]$. The materials used in ocular prostheses should have appropriate properties (i.e., excellent biocompatibility, durability, excellent aesthetics and non-irritating to the eye socket [7,8]. The method of constructing the ocular prostheses involved several steps: Recording the master impression; making the wax pattern and trying it into the eye socket; investing the wax pattern; iris production and then processing with acrylic resins [9, 10]. White coloured acrylic materials, which are usually used to fabricate the scleral part of the ocular prosthesis, are not available in the local markets. Special dyes (i.e. oil paints), hence, must be added in order to match the colour of normal eye [11, 12]. According to the literature, various researches have been carried out to investigate the mechanical and physical properties of acrylic ocular prosthesis under the influence of different disinfectants and fillers. Regarding disinfectants, it was found that $1 \%$ hypochlorite and $4 \%$ chlorhexidine have significantly reduced hardness of acrylic resins [13]. On the other hand, the titanium dioxide fillers have significantly decreased flexural strength of acrylic resin $[14,15]$.

Besides, the literature indicated that the use of white oil paints (titanium dioxide) has considerably improved hardness of acrylic resin [16, 17]. The null hypothesis stated that there are no significant differences between the experimental and control groups. The purpose of this study was to assess the effect of adding white oil paints on impact strength of acrylic resin materials.

\section{MATERIALS AND METHODS}

\subsection{Materials}

In this study, 20 samples of acrylic resin (Spofadental, Jicin, Czech Republic) were produced. These samples were divided into two main groups and each group had 10 samples. The first group was considered as the control without the addition of oil paints; and the second group (experimental) included the addition of $1 \mathrm{ml}$ of titanium oil paints (Grumbacher, Leeds, Alabama, USA) (Fig. 1). The dental stone (Zhermack, Badia Polesine, Rovigo, Italy) was utilized to make the moulds, and the petroleum jelly (Hebei, Shijiazhuang, China) and tin foil (Zinnfoile, Dentaurum Pforzheim, Starke: $0.01 \mathrm{~mm}$, Germany) were used as the separation medium.

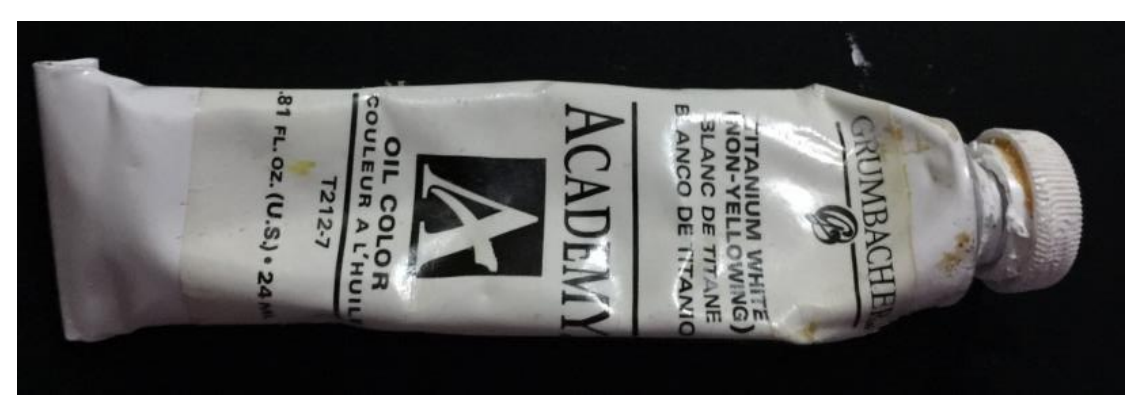

Fig. (1). Grumbacher titanium white.

\subsection{Sample Preparation}

For impact strength test, acrylic samples were prepared via plastic models, which were customized with dimensions of $80 \mathrm{~mm}$ length, $10 \mathrm{~mm}$ width, and $4 \mathrm{~mm}$ thickness according to ISO 179-1:2000 as shown in Fig. (2) [18]. The process of fabricating the acrylic samples starts by coating the lower and upper parts of the metal flask with Vaseline to allow removal of acrylic samples from stone mould following de-flasking [19]. The dental stone and water were handmixed according to the manufacturer's instructions. At creamy state, the mixture was placed into the lower half of the flask, and plastic patterns were carefully positioned in the center,taking into consideration that half of them must be visible in order to be easily removed from the stone mould as illustrated in Fig. (2). 


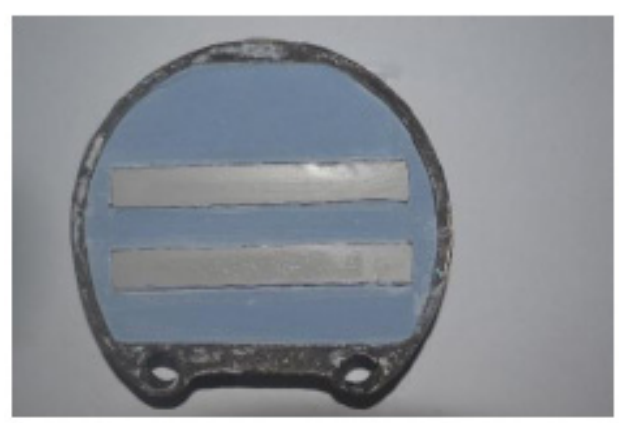

Fig. (2). The dental stone mould and the plastic strips.

Following the complete set of the stone surface, the tinfoil separating medium was applied; and another mixture of dental stone and water was prepared, and applied over stone surface and patterns. The mould was then left for one hour to set. Following that, upper and lower parts were carefully opened; patterns were removed and then cleaned with detergents before applying the separating medium (Fig. 3).

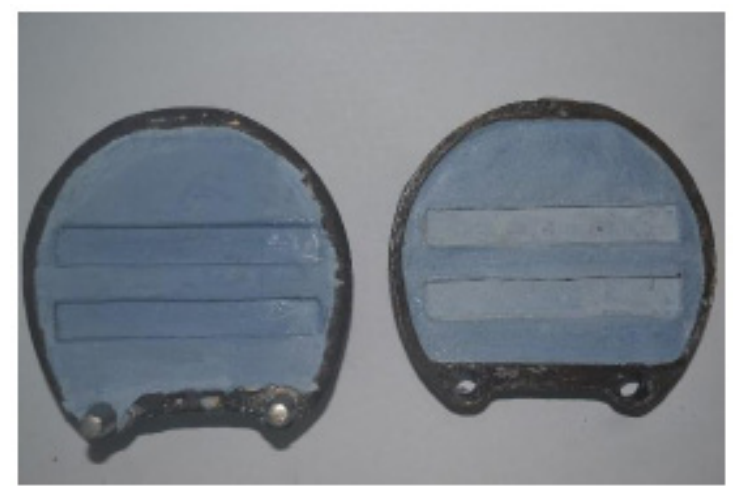

Fig. (3). Two part mould.

According to the manufacturer's instructions, $22 \mathrm{~g}$ of the acrylic powder and $10 \mathrm{ml}$ of the monomer were mixed for the control group. When the mixture reached to form a dough, it was then packed into the mould, the flask was then put under the hydraulic press and then cured. Following curing, the flask was left to cool, and acrylic samples were carefully removed, finished and polished [19]. The experimental groups (white oil paint), on the other hand, were fabricated from heat cured acrylic resin byadding $22 \mathrm{~g}$ acrylic powder, $9 \mathrm{ml}$ monomer, and $1 \mathrm{ml}$ oil paint [12]. All acrylic samples were then stored in water for two days at $37 \mathrm{C}^{\circ}$ before conducting the impact strength test [19].

\subsection{Impact Strength Test}

The Charpy's impact strength tester (Tinius Olsen, Houston, Texas, USA) was used to determine the strength of acrylic samples as shown in Fig. (4). All the samples were positioned on the bending fixture and then the load was applied till fracture occurred (Fig. 5). The impact strength of the un-notched specimen was measured in $\mathrm{KJ} / \mathrm{M}^{2}$ and the following formula was used to measure impact strength values.

Impact strength $\left(\mathrm{KJ} / \mathrm{M}^{2}\right)=\mathrm{E} / \mathrm{B} . \mathrm{D} \times 10^{3}[18]$.

Where the letter E represents the impact absorbed energy.

The letter " $\mathrm{B}$ " represents the width of the sample, which is measured in millimeter.

the letter " $D$ " represents the thickness of the sample, which is measured in millimeter. 


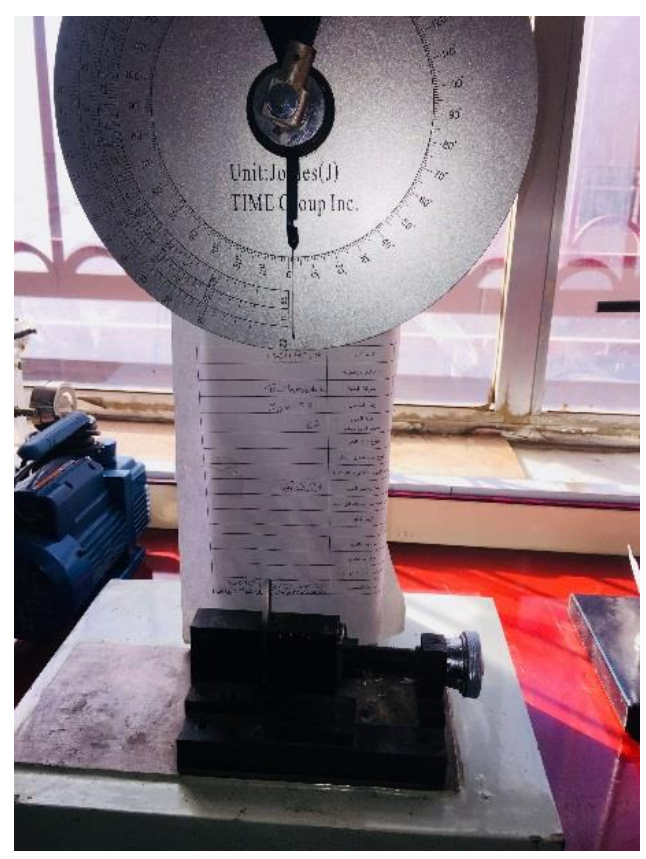

Fig. (4). Impact strength tester.

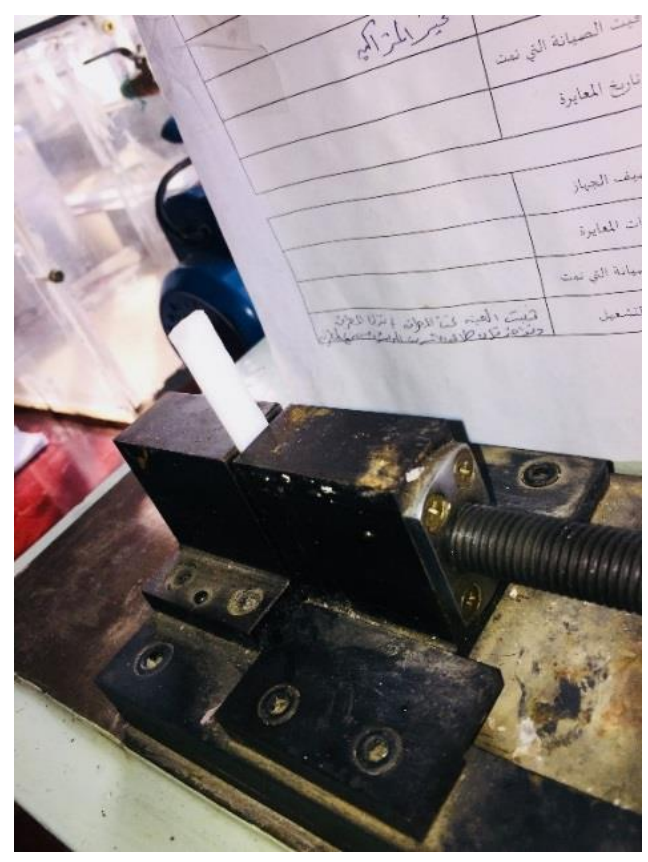

Fig. (5). Sample under test.

\section{RESULTS}

According to the statistical analysis (SPSS v.20 software; IBM, North castle, New York, USA), a statistically significant decrease in the impact strength after adding the white oil paints was found (independent $\mathrm{T}$ test; $P<0.001$ ). The impact strength of the experimental group was $5.97+1.11 \mathrm{KJ} / \mathrm{M}^{2}$ whereas the impact strength of the acrylic samples which were not tinted with white oil paints was $9.42+1.32 \mathrm{KJ} / \mathrm{M}^{2}$.

\section{DISCUSSION}

Acrylic materials are widely used in many applications in the field of dentistry and maxillofacial prostheses (i.e. ocular prostheses) due to their suitable chemical, mechanical and physiological properties. White acrylic resins are utilized for the fabrication of the scleral part of the ocular prosthesis; such substances are not available in the local markets. It is necessary, therefore, to use special dyes (i.e. white oil paints) to match the color of the natural eye. The 
aim of the present study was to assess the effect of white oil paints (titanium white) on the acrylic resins in terms of impact strength. The study included two groups, the first group was considered as control and the other group which involved the use of white oil paints with a concentration of $1 \mathrm{ml}$ was considered as experimental. The current results revealed that there was a significant decrease in the mean values of impact strength of acrylics following using white oil paints. The decrease in the impact strength values might be due to the weaker bond between the titanium dioxide filler and matrix. For this reason, the crack propagation was increased. The current study contradicts the research conducted by Alwan and Alameer (2015) [20], who reported that the addition of titanium dioxide has increased the impact strength of acrylic resins as such fillers form a stronger bond between polymer chains because of their smaller size. According to the present results, the null hypothesis was rejected as there were significant differences between the control and experimental groups where $P$-value $<0.001$.

\section{CONCLUSION}

The results concluded that the oil paints would have a negative effect on the impact strength of the acrylic resins. It is recommended to use different pigments, which would have no negative effect on the impact strength of the acrylic resin.

\section{LIST OF ABBREVIATIONS}

$\begin{array}{lll}\mathbf{m m} & = & \text { millimeter } \\ \mathbf{m l} & = & \text { milliliter } \\ \mathbf{g} & = & \text { gram }\end{array}$

\section{ETHICS APPROVAL AND CONSENT TO PARTICIPATE}

The article does not need Ethics Approval and Consent to Participate.

\section{HUMAN AND ANIMAL RIGHTS}

No animals/ humans were used in this research.

\section{CONSENT FOR PUBLICATION}

Not applicable.

\section{CONFLICT OF INTEREST}

The authors declare no conflict of interest, financial or otherwise.

\section{ACKNOWLEDGEMENTS}

Special thanks to Mr. Mukhalid, the director of Material Lab, at the University of Technology, Department of Materials for his help in performing the impact strength test.

\section{REFERENCES}

[1] Raflo GT. Enucleation and evisceration. Duane's clinical ophthalmology. Revised ed. Philadelphia: Lippincott-Raven 1995 ; Vol. 5: pp. 1-25.

[2] Kaur A, Pavaiya A, Singh S, Singh R, Chand P. A simplified approach to fabrication of an ocular prosthesis: A case series. Indian J Dent Res 2010; 21: 615-7.

[http://dx.doi.org/10.4103/0970-9290.74236]

[3] Jain DC, Hegde V, Aparna IN, Dhanasekar B. Ocular prosthesis an esthetic vision. J Nepal Den Asso 2010; 11(1): 101-6.

[4] Dheeraj K, Ajay G, Hemant G, Gaurav V. Ocular prosthesis: A case report. Baba Farid University Dental J 2010; 1(1): 52-4.

[5] Nafij BJ, Theerathavaj S, Mohammad KA. A complete procedure of ocular prosthesis: A case report. Int Med J 2013; 20: 729-30.

[6] Raizada K, Rani D. Ocular prosthesis. Contact Lens \& Anterior Eye 2007; 30(3): 152-62. [http://dx.doi.org/10.1016/j.clae.2007.01.002]

[7] Goiato MC, Nicolau EI, Mazaro JV. Mobility, aesthetic, implants, and satisfaction of the ocular prostheses wearers. Craniofac Surg J 2010; 21(1): 160-4.

[http://dx.doi.org/10.1097/SCS.0b013e3181cfe898]

[8] Fernandes AU, Goiato MC, Santos DM. Effect of weathering and thickness on the superficial micro-hardness of acrylic resin and ocular button. J Contact Lens Anterior Eye 2009; 32(6): 283-7. 
[http://dx.doi.org/10.1016/j.clae.2009.09.001]

[9] Cevik P, Dilber E, Oguz Eraslan O. Different techniques in fabrication of ocular prosthesis. J Craniofac Surg 2012; 23(6): $1779-81$. [http://dx.doi.org/10.1097/SCS.0b013e31826701bb]

[10] Sethi T, Kheur M, Haylock C, Harianawala H. Fabrication of a custom ocular prosthesis. Middle East Afr J Ophthalmol 2014; 21(3): 271-4. [http://dx.doi.org/10.4103/0974-9233.134694]

[11] González L, Santana F, Castillo R, Ríos A. Accelerated physical deterioration of in vitro ocular prostheses. Rev Odontol Mex 2012; 16(1): 14-7.

[12] Fernandes AU, Goiato MC, Batista MA, Santos DM. Color alteration of the paint used for iris painting in ocular prostheses. Braz Oral Res 2009; 23(4): 386-92. [http://dx.doi.org/10.1590/S1806-83242009000400007]

[13] Moreno A, Goiato M, Santos D, Haddad M, Pesqueira A, Bannwat L. Effect of different disinfectants on the microhardness and roughness of acrylic resins for ocular prosthesis. Gerodontology 2013; 30(1): 32-9. [http://dx.doi.org/10.1111/j.1741-2358.2012.00642.x]

[14] Andreotti AM, Goiato MC, Moreno A, Nobrega AS, Pesqueira AA, dos Santos DM. Influence of nanoparticles on color stability, microhardness, and flexural strength of acrylic resins specific for ocular prosthesis. Int J Nanomedicine 2014; 9(1): $5779-87$.

[15] Kati F, Al-Kaabi A. Part II: Effect of oil paint addition on the flexural strength of acrylic ocular prosthesis. Proceed $3^{\text {rd }}$ Cong Medical and Health Special 2016; 4(4):100-4.

[16] Kati F, Al-Kaabi A, Part I. Effect of oil paint addition on micro hardness of acrylic ocular prosthesis. Iraqi Dent J 2016; $38(2)$ : 87-9. [http://dx.doi.org/10.26477/idj.v38i2.83]

[17] Al-shammari F. Effect of metal oxides on some mechanical properties of clear acrylic specific for artificial eye. Mustansiria Dental J 2016; 13(1): 77-84.

[18] Plastics. Determination of Charpy impact properties Part 1: Non-instrumented impact test ISO 179-1. $1^{\text {st }}$ ed. 2000.

[19] American national standers institute/ American dental association specification No12 for denture base polymer. $10^{\text {th }}$ ed. Chicago: Council on Dental Material and Devices 1999.

[20] Alwan S, Alameer S. The effect of the addition of silanised Nano titania fillers on some physical and mechanical properties of heat cured acrylic denture base materials. J Baghdad Coll Dentistry 2015; 27(1): 86-91. [http://dx.doi.org/10.12816/0015269]

\section{(C) 2018 Firas Abd Kati.}

This is an open access article distributed under the terms of the Creative Commons Attribution 4.0 International Public License (CC-BY 4.0), a copy of which is available at: (https:/creativecommons.org/licenses/by/4.0/legalcode). This license permits unrestricted use, distribution, and reproduction in any medium, provided the original author and source are credited. 